\title{
THE USE OF CHICKEN IGY IN A DOUBLE ANTIBODY SANDWICH ELISA FOR THE QUANTIFICATION OF MELITTIN IN BEE VENOM AND BEE VENOM MELITTIN CONTENT IN COSMETICS
}

\author{
Lindsey Y. K. Suh ${ }^{1}$ \\ Tayabaa Kartoon ${ }^{1}$ \\ Naiyana Gujral ${ }^{1}$ \\ Youngmee Yoon
Joo Won Suh
Hoon Sunwoo \\ ${ }^{1}$ Faculty of Pharmacy and Pharmaceutical Sciences, University of Alberta, \\ Edmonton, Alberta, Canada T6G 2E1 \\ ${ }^{2}$ Center for Nutraceutical and Pharmaceutical Materials, Myongji University, \\ Cheoin-gu, Yongin, Gyeonggi-Do 449-728, Republic of Korea \\ *corresponding author: hsunwoo@ualberta.ca \\ Received 12 November 2014; accepted 30 April 2015
}

\begin{abstract}
A bstract
Two enzyme-linked immunosorbent assay (ELISA) - based detection systems: indirect competitive ELISA and biotinylated double antibody sandwich ELISA (DAS-ELISA) were developed to determine the melittin concentration in honeybee (Apis mellifera) venom and the melittin concentration in cosmetics which contain bee venom. The indirect competitive ELISA employed chicken anti-melittin IgY. The biotinylated DAS-ELISA employed anti-melittin monoclonal antibody (MAb) and biotinylated anti-melittin IgY. To produce anti-melittin IgY; Sigma melittin was emulsified with Freund's incomplete adjuvant and immunised to Leghorn laying chickens intramuscularly at four different sites $(50 \mu \mathrm{g} / \mathrm{mL}, 0.25 \mathrm{~mL}$ per site) of the breast muscles. After 5 to 8 weeks of the immunisation, anti-melittin IgY was extracted and analysed by ELISA. The anti-melittin IgY antibody produced was highly specific to melittin and did not cross-react with other bee venom proteins, as examined by ELISA and a western-blot assay. Indirect competitive ELISA demonstrated a higher range of melittin detection $(2.5$ to $80 \mu \mathrm{g} / \mathrm{mL})$. Double antibody sandwich ELISA using MAb as the capture antibody and biotinylated polyclonal IgY as the detection antibody, provided a lower range of detection $(2.5-40 \mathrm{ng} / \mathrm{mL})$, which has a 1000 times higher sensitivity than that of indirect competitive ELISA. Therefore, indirect competitive ELISA is a useful tool to measure the concentration of melittin in bee venom as a raw material. Biotinylated DAS-ELISA, on the other hand, is more suitable for nanoscale quantification of melittin in commercial products.
\end{abstract}

Keywords: bee venom, DAS-ELISA, immunoglobulin Y, indirect competitive ELISA, melittin, monoclonal antibody.

\section{INTRODUCTION}

Bee venom, also known as apitoxin, is a blend of active compounds composed of enzymes, peptides, phospholipids, sugars, amines, and minerals. Melittin is the principal toxic component of bee venom that accounts for $50 \%$ of the bee venom dry weight. Melittin is a 26 amino acid long peptide (2.8 kDa) and has the chemical formula $\mathrm{C}_{131} \mathrm{H}_{228} \mathrm{~N}_{38} \mathrm{O}_{32}$, and the amino acid sequence of GIGAVLKVLTTCLPALISWIKRKRQQ-NH2 (Habermann, 1972; Gauldie et al., 1978).

Several researches have reported that melittin is a potent therapeutic agent in the treatment of cancerous tumors, arthritis, and rheumatism (Park et al., 2004; Gajski and Garaj-Vrhovac, 2013; Koh et al., 2013). Melittin is most extensively studied for its antibacterial property. This water-soluble amphipathic peptide spontaneously associates with and partitions into lipid bilayer, in which it adopts a bent $\alpha$-helical structure. At low concentrations, melittin causes transient permeabilisation of the cytoplasmic membrane and collapses the electrochemical gradient. Stable pore formation is observed at higher concentrations of melittin, resulting in size-independent leakage of macromolecules and cell lysis (Terwilliger et al., 1982; Raghuraman and Chattopadhyay, 2007; Lee et al., 2013). 
Melittin has also been reported to suppress the expression of pro-inflammatory cytokines triggered by Propionibacterium acnes ( $P$. acnes) through regulation of the NF-kB and MAPK signaling pathways (Lee at el., 2014a). Propionibacterium acnes is a gram-positive skin resident bacteria that causes inflammatory acne vulgaris; the most common skin disease affecting $80 \%$ of individuals (Leyden, 2001; Bojar and Holland, 2004).

The anti-microbial and anti-inflammatory activities of melittin have raised a commercial interest in treating bacteria-caused skin problems and diseases. However, great care needs to be taken over the amount incorporated into commercial products due to the cytotoxicity of melittin (Jamasbi et al., 2014). Reliable quantification assays are needed for melittin which specify the endogenous levels in bee venom, and which specify the supplemental levels of melittin used in cosmetic formulations. A recently used method of melittin quantification is High Performance Liquid Chromatography (HPLC). This method requires a laborious sample preparation, costly reagents, and great expertise (Haghi et al., 2013). Although it can determine a concentration with satisfactory accuracy, HPLC is less practical when quantifying a bulk mixture of proteins. This is particularly true when quantifying bee venom and cosmetic products in the presence of molecules with similar molecular weight. Quantitative ELISA becomes a competitive option in terms of time consumption, cost-effectiveness, and detection of specific protein content, in a mixture with molecular size similarity. However, there is no report on the quantification of melittin using ELISA. The use of chicken IgY in the ELISA system has proven to be economical and efficient at detecting a wide range of proteins in serum and biological samples (Larsson et al., 1991; Schade et al., 2005).

The present study was undertaken to develop an ELISA system based on polyclonal anti-melittin IgY obtained from chicken egg yolks for detection of melittin in bee venom. The detection systems were further validated for the testing of mellitin in commercially available cosmetics which contain bee venom.

\section{MATERIAL AND METHODS}

\section{Chemicals}

The following: $97 \%$ purity melittin, Freund's incomplete adjuvant, purified chicken immunoglobulin G $(\lg G)$, rabbit anti-chicken $\lg G$, horseradish peroxidase (HRP) conjugated rabbit anti-chicken
IgG, streptavidin-HRP, and tetramethylbenzidine (TMB) liquid substrate system for membranes were purchased from Sigma (St. Louis, MO, USA). Biotinaimdohexanoic acid-3-sumelittino-N-hydroxysuccinimide ester (NHS-PEO ${ }_{4}$-Biotin) was from Fisher Scientific Canada (Ontario, Canada). Tetramethylbenzidine substrate was from KPL (Gaithersburg, MD, USA). Anti-melittin MAb was donated by Myungi University (Yong In, Korea). A Bio-Rad protein assay kit was purchased from Bio-Rad Laboratory (Ontario, Canada). Lyophilized Apis mellifera bee venom was donated by South Korean honeybee farms. Two overthe-counter cosmetic creams containing purified bee venom were purchased from a local store.

\section{Instrumentation}

Sephacryl S-300 and S-100 gel filtration column were from GE Healthcare (Quebec, Canada). Microtiter 96-well plates were from Costar Inc. (Cambridge, MA, USA). The ELISA $V_{\max }$ kinetic microplate reader was from Molecular Devices Corp (Sunnyvale, CA, USA). Slide-A-Lyzer ${ }^{\oplus}$ was purchased from Thermo Scientific Pierce Protein Research Products (Ontario, Canada). The BioLogic Duoflow chromatography system was from Bio-Rad (Ontario, Canada).

\section{Separation of melittin from bee venom Size exclusion chromatography}

The components of bee venom were separated using Sephacryl S-100 column $(1 \times 100 \mathrm{~cm})$. The column was equilibrated with phosphate buffered saline (PBS) on Bio-Rad BioLogic Duoflow chromatography systems. The bee venom was homogenised in PBS $(100 \mathrm{mg} / \mathrm{mL})$ and centrifuged at $4000 \mathrm{rpm}$ for $5 \mathrm{~min}$. Supernatants were filtered through a $0.45 \mu \mathrm{m}$ filter and applied on the gel filtration column at a consistent flow rate of $4.2 \mathrm{~mL} / \mathrm{h}$ at $4^{\circ} \mathrm{C}$. One $\mathrm{mL}$ of fraction was collected per tube for 24 hours. The column effluent was monitored with a UV detector set at $280 \mathrm{~nm}$.

\section{SDS-PAGE}

Each fraction obtained by size exclusion chromatography was further analysed by sodium dodecyl sulfate polyacrylamide gel electrophoresis (SDS-PAGE) under non-reducing conditions. Each fraction was mixed with a sample buffer $(\mathrm{pH} 6.8$, $0.0625 \mathrm{M}$ Tris- $\mathrm{HCl}, 2 \%$ SDS, $10 \%$ glycerol, and $0.002 \%$ bromophenol blue) at a 1:1 ratio. Electrophoresis was performed at $110 \mathrm{~V}$ for $1.5 \mathrm{~h}$, in TrisGlycine running buffer ( $\mathrm{pH} 8.3,0.025 \mathrm{M}$ Tris, $0.192 \mathrm{M}$ glycine, $0.1 \%$ SDS) on a $10 \%$ acrylamide separating gel. 
Production, purification, concentration, and specificity of anti-melittin polyclonal $\lg Y$ Production of anti-melittin polyclonal IgY

Production of polyclonal IgY directed against melittin was carried out as previously described by Sunwoo et al. (2011). Sigma melittin was suspended in sterilised PBS $\left(0.14 \mathrm{M} \mathrm{NaCl}, 0.0015 \mathrm{M} \mathrm{KH}_{2} \mathrm{PO}_{4^{\prime}}\right.$ $0.0081 \mathrm{M} \mathrm{Na}_{2} \mathrm{HPO}_{4}, 0.0027 \mathrm{M} \mathrm{KCl}, \mathrm{pH} 7.2$ ) at a concentration of $100 \mu \mathrm{g} / \mathrm{mL}$ and emulsified with an equal volume of Freund's incomplete adjuvant. Twelve, 23-week-old, Single Comb White Leghorn chickens were intramuscularly injected with the emulsified saline with or without melittin at four different sites ( $0.25 \mathrm{~mL}$ per site) of breast muscles (two sites per left or right breast muscle). A booster immunisation was given after two weeks of the initial immunisation. Eggs were collected daily for 8 weeks and stored at $4^{\circ} \mathrm{C}$ until the antibody extraction.

\section{Purification of IgY}

The egg yolk from immunised hens was manually separated from the egg white. The egg yolk was then diluted 1:6 by gently mixing with cold distilled water ( $\mathrm{pH}$ adjusted to 4.0 with $0.1 \mathrm{M} \mathrm{HCl}$ ) and further diluted to a final dilution of 1:10 with cold acidified distilled water ( $\mathrm{pH}$ 2.0), adjusted to a final $\mathrm{pH}$ of 5.4, and incubated for $12 \mathrm{~h}$ at $4^{\circ} \mathrm{C}$. The lipid granules of the yolk were sedimented by centrifugation $\left(3,125 \times \mathrm{g}\right.$ for $20 \mathrm{~min}$ at $\left.4^{\circ} \mathrm{C}\right)$, and the IgY-rich water-soluble fraction (WSF) was collected. Anti-melittin IgY antibodies in the WSF were further purified by ammonium sulfate (60\%) followed by a Sephacryl S-300 gel filtration column. Purified IgY was freeze-dried for further use.

\section{Titer of anti-melittin polyclonal lgY in egg yolks using indirect ELISA}

Unless otherwise stated, the microtiter plate was washed four times with PBS containing $0.05 \%$ Tween 20 (PBST), between each step. A microtiter plate which had 96-wells was coated with Sigma melittin (100 $\mu \mathrm{L}$ per well), in carbonate-bicarbonate buffer (0.05 M, pH 9.6) at a concentration of $10 \mu \mathrm{g} / \mathrm{mL}$, and incubated for $1 \mathrm{~h}$ at $37^{\circ} \mathrm{C}$. Unbound sites were blocked with $100 \mu \mathrm{L}$ of $3 \%$ bovine serum albumin (BSA) in PBST by incubating at $37^{\circ} \mathrm{C}$ for $1 \mathrm{~h}$. After washing, the IgY-rich WSF (diluted 1:1000 in PBST) from egg yolks of melittin-immunized hens, or from egg yolks of the non-immunised control hens, was added (100 $\mu \mathrm{L}$ per well), and then incubated at $37^{\circ} \mathrm{C}$ for $1 \mathrm{~h}$. After washing, $100 \mu \mathrm{L}$ of rabbit anti-chicken IgG conjugated with horseradish peroxidase (HRP diluted 1:5000 in PBST) was added and incubated at $37^{\circ} \mathrm{C}$ for $1 \mathrm{~h}$. Color was developed with $100 \mu \mathrm{L}$ of freshly prepared tetramethylbenzidine (TMB) substrate for $30 \mathrm{~min}$, and absorbance was taken at $\mathrm{OD}_{650}$ on the ELISA $\mathrm{V}_{\max }$ kinetic microplate reader. A determination was made of the $O D$ value of antimelittin IgY, by subtracting the value of the control antibody from that of melittin-specific antibody.

\section{Total IgY concentration}

To obtain the total IgY concentration, indirect ELISA was performed as above with some modifications. The enzyme-linked immunosorbent assay (ELISA) plate was coated with $100 \mu \mathrm{L}$ per well of rabbit antichicken $\mathrm{gG}$, at a final concentration of $2 \mu \mathrm{g}$. Two-fold serial dilutions of sigma chicken lgG in PBS ( 0.5 to $0.031 \mu \mathrm{g} / \mathrm{mL}$ ) were used as the reference antibody to prepare a standard curve. Freeze-dried samples of IgY were reconstituted in PBS and added to wells on the same plate. The total IgY concentration was determined using a standard curve.

\section{Western Blot}

As described above, a SDS-PAGE of purified (fraction III) and Sigma melittin was performed. The proteins were electrophoretically transferred from gel onto a nitrocellulose membrane at $100 \mathrm{~V}$ for $1 \mathrm{~h}$ in transfer buffer (pH 8.5, $120 \mathrm{mM}$ glycine, $120 \mathrm{mM}$ Tris). Unless otherwise stated, the membrane was washed four times with Tris buffer containing 0.05\% Tween-20 (Tris-T) between each step. Non-specific binding was blocked with $3 \% \mathrm{BSA}$ in Tris buffer $(\mathrm{pH}$ 8.0, $5 \mathrm{mM}$ Tris- $\mathrm{HCl}, 0.15 \mathrm{M} \mathrm{NaCl}$ ) at room temperature for $1 \mathrm{~h}$. After blocking, the membrane was incubated with anti-melittin $\lg Y(10 \mathrm{mg} / \mathrm{mL}, 1: 1,000$ dilution in Tris-T) at room temperature for $2 \mathrm{~h}$, followed by $1 \mathrm{~h}$ of incubation with HRP-conjugated rabbit anti-chicken IgG (1:2000 dilution in Tris-T). After washing, the membrane was treated with a TMB liquid substrate system for color development.

\section{Specificity of anti-melittin IgY}

The cross-reactivity between IgY towards other bee venom proteins in fraction I, II, and IV obtained from size-exclusion chromatography, was determined by indirect ELISA with some modifications. The enzyme-linked immunosorbent assay plate was coated with $100 \mu \mathrm{L}$ triplicates of each fraction and purified melittin (fraction III) in carbonate-bicarbonate buffer $(10 \mu g$ of protein/mL). Freeze-dried anti-melittin IgY powder was reconstituted with PBST at a dilution of 1:1,000 and $100 \mu \mathrm{L}$ was added per well. The reactivity of anti-melittin IgY to each fraction was determined by a comparison to the reactivity against purified melittin. 
Development of the ELISA detection method for quantification of melittin in bee venom and for quantification of melittin in cosmetic products which contain bee venom Indirect competitive ELISA

In test tubes, anti-melittin IgY reconstituted in PBS $(1 \mu \mathrm{g} / \mathrm{mL})$ was pre-incubated $\left(4^{\circ} \mathrm{C}\right.$ overnight) with a two-fold serial dilution of purified melittin ( 0 to $160 \mu \mathrm{g} / \mathrm{mL}$ ) for standard, and lyophilised whole bee venom powder diluted in PBS (100 $\mu / \mathrm{mL})$. Unless otherwise stated, there were four washings with PBST conducted between each step of ELISA. The microtiter plate was coated with $100 \mu \mathrm{L}$ per well of purified melittin (10 $\mu / \mathrm{mL}$ in PBS) by incubating at $4^{\circ} \mathrm{C}$ overnight. The following day, the wells were blocked with $120 \mu \mathrm{L}$ of $3 \% \mathrm{BSA}\left(37^{\circ} \mathrm{C}\right.$ for $45 \mathrm{~min}$ ). The pre-incubated mixtures of melittin and lgY were added to each well $(100 \mu \mathrm{L})$ and incubated at $37^{\circ} \mathrm{C}$ for $1 \mathrm{~h}$. Horseradish peroxide conjugated rabbit anti-chicken IgG at a 1:3,000 dilution was added to $100 \mu \mathrm{L}$ per well and incubated at $37^{\circ} \mathrm{C}$ for $1 \mathrm{~h}$. Color was developed with $100 \mu \mathrm{L}$ of TMB for $5 \mathrm{~min}$. Absorbance was measured at $650 \mathrm{~nm}$ using the ELISA $V_{\max }$ kinetic microplate reader. The concentration of melittin in bee venom was determined using a standard curve.

\section{Biotinylation of anti-melittin lgY}

Biotin conjugation was carried out according to the manufacturer's instruction. One mg of anti-melittin $\mathrm{lgY}$ in PBS (pH 7.2) was incubated with $20 \mu \mathrm{L}$ of long arm NHS-PEO -Biotin (3 mg/mL) at room temperature for $1 \mathrm{~h}$. The solution was mixed with $10 \mu \mathrm{L}$ glycine $(100 \mu \mathrm{g} / \mu)$ by gently shaking the mixture for $10 \mathrm{~min}$, followed by dialysis in a Slide-A-Lyzer against PBS (pH 7.2) at $4^{\circ} \mathrm{C}$ overnight. To test the conjugation of biotin to lgY antibodies, the biotinylated antibodies were diluted 1:10, 1:100, and 1:1,000 and blotted onto a nitrocellulose membrane, followed by a $1 \mathrm{~h}$ incubation at room temperature. The membrane was washed three times with PBS $(\mathrm{pH} 7.2)$ and blocked with $5 \% \mathrm{BSA}$ for $2 \mathrm{~h}$, followed by incubation with streptavidin-HRP $(1: 1,000)$ at room temperature for $1 \mathrm{~h}$. After washing, a TMB substrate for membranes was added for color development.

\section{Biotinylated Double Antibody Sandwich (DAS) ELISA}

Unless otherwise stated, washing was done four times with PBST between each step. A microtiter plate was coated with $100 \mu \mathrm{L}$ of anti-melittin MAb
$(1 \mu \mathrm{g} / \mathrm{mL})$ in $0.05 \mathrm{M}$ carbonate buffer $\left(\mathrm{pH} \mathrm{9.6)}\right.$ at $4^{\circ} \mathrm{C}$ overnight. Nonspecific binding sites were blocked with $120 \mu \mathrm{L}$ of $3 \%$ BSA for 45 min. After blocking, $100 \mu$ of purified melittin standard in a two-fold serial dilution (0 to $160 \mathrm{ng} / \mathrm{mL}$ ), lyophilised whole bee venom powder $(0-500 \mathrm{ng} / \mathrm{mL})$, and two melittin containing cosmetic samples (1:2000, 1:4000, and $1: 8000$ ) in PBST were added and incubated at $37^{\circ} \mathrm{C}$ for $1 \mathrm{~h}$. After washing, $100 \mu \mathrm{L}$ of the biotinylated anti-melittin lgY $(1 \mu \mathrm{g} / \mathrm{mL})$ was added to each well and incubated at $37^{\circ} \mathrm{C}$ for $1 \mathrm{~h}$. Streptavidin-HRP (1:1000) was added and incubated at $37^{\circ} \mathrm{C}$ for $45 \mathrm{~min}$. After 10 min of color development with TMB, absorbance was taken at $\mathrm{OD}_{650}$ using an ELISA $\mathrm{V}_{\max }$ kinetic microplate reader. A determination of the ELISA value of antibody activity was done by subtracting the value of the control antibody from that of specific antibody. The concentration of melittin in bee venom and of melittin in those cosmetic samples which contain bee venom was determined by a standard curve.

\section{Validation}

The limit of quantification (LOQ) was calculated from 10 times the standard error of the predicted $\mathrm{OD}$ value for each standard melittin concentration in a regression divided by the slope.

Assay precision was determined by intra-assay (within plate; $n=10$ ) and inter-assay (between plates; $n=8$ ) variation.

\section{Statistical analysis}

Results were subjected to the analysis of variance using the SAS Software (SAS Institute, Inc., Cary, NC) and statistical significance of differences $(p<0.05)$ was evaluated by the least significant difference procedure. The student t-test (one-tailed t-test) was used to analyse the significant difference $(p<0.05)$ between the groups.

\section{RESULTS}

Purification of melittin from bee venom by size exclusion chromatography

Figure 1a illustrates four Sephacryl chromatography separated fractions of bee venom components (I - IV) based on the molecular weight. Each fraction was electrophoresised and protein presence was observed in fraction I (30 - $250 \mathrm{kDa})$, II (10 - $25 \mathrm{kDa})$, and III (2 - $15 \mathrm{kDa}$ ) (Fig. 1b). The band corresponding to the molecular weight of melittin (2.8 kDa) suggests melittin presence in fraction III. 
Production of IgY antibody against melittin The anti-melittin IgY antibodies obtained from egg yolks of immunised chickens were pooled weekly and titrated by the indirect ELISA (Fig. 2). The titer of anti-melittin IgY was undetectable on day 0 , rapidly increased from week 2 to week 4 ( $p<0.05)$, and thereafter remained relatively constant for up to 8 weeks. The eggs obtained from 5 to 8 weeks were found to have high levels of anti-melittin IgY activity. The total IgY content in the egg yolk was constant ( $46.85 \pm 1.48 \mathrm{mg} / \mathrm{mL}$ ) among the melittinimmunised chickens during weeks 5 to 8 . There was no significant difference in the total $\lg Y$ amount compared to the non-immunised eggs (42.07 \pm

a)

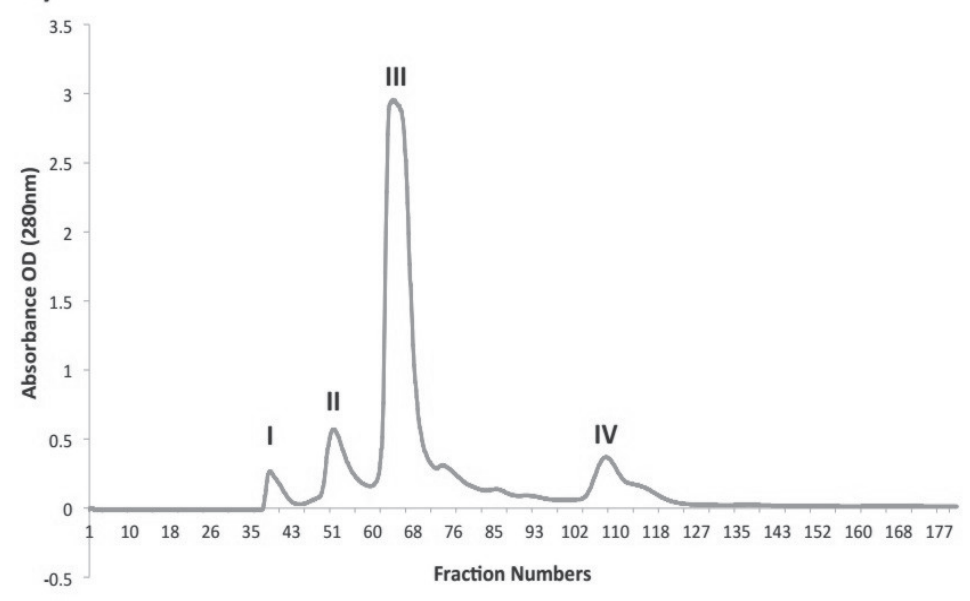

$1.34 \mathrm{mg} / \mathrm{mL}$ ). Indirect ELISA results demonstrated $11.7 \%$ of anti-melittin IgY concentration in total $\mathrm{lgY}$ in the immunised group $(5.48 \pm 0.62 \mathrm{mg} / \mathrm{mL})$, whereas the melittin-specific lgY was not detected in the control group.

\section{Specificity of anti-melittin polyclonal IgY}

The presence of melititn in fraction III as well as the reactivity of purified anti-melittin IgY against melittin was confirmed by western blot assay. The band at 2 - $10 \mathrm{kDa}$ in fraction III has the same molecular weight and band pattern as that of Sigma melittin (Fig. 3). Therefore, fraction III was used as purified melittin for further experiments. Western blot results showed that anti-melittin IgY antibody

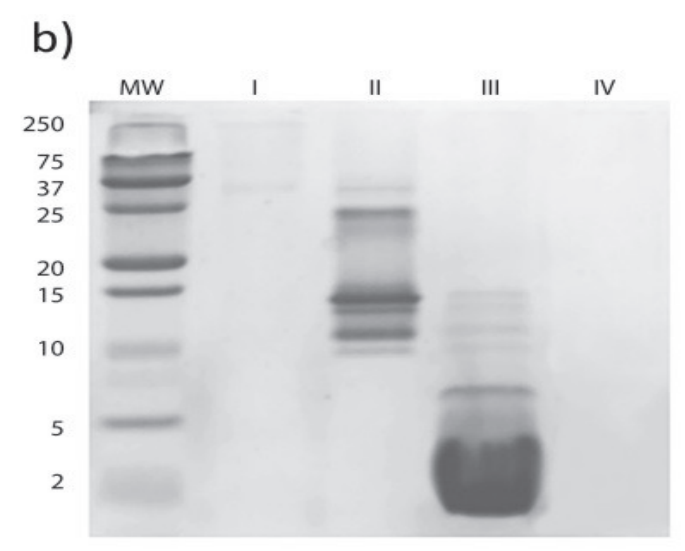

Fig. 1. (a) Size-exclusion chromatography of crude bee venom showing four main peaks. Purified bee venom was filtered through Sephacryl S-100 column at a flow rate of $4.2 \mathrm{~mL} / \mathrm{h}$ at $4^{\circ} \mathrm{C}$ for 24 hours. Absorbance was taken at OD $=280 \mathrm{~nm}$. (b) SDS-PAGE of size-exclusion chromatography fractions. Fractions I to IV were run on a non-reducing gel. MW - Molecular weight.

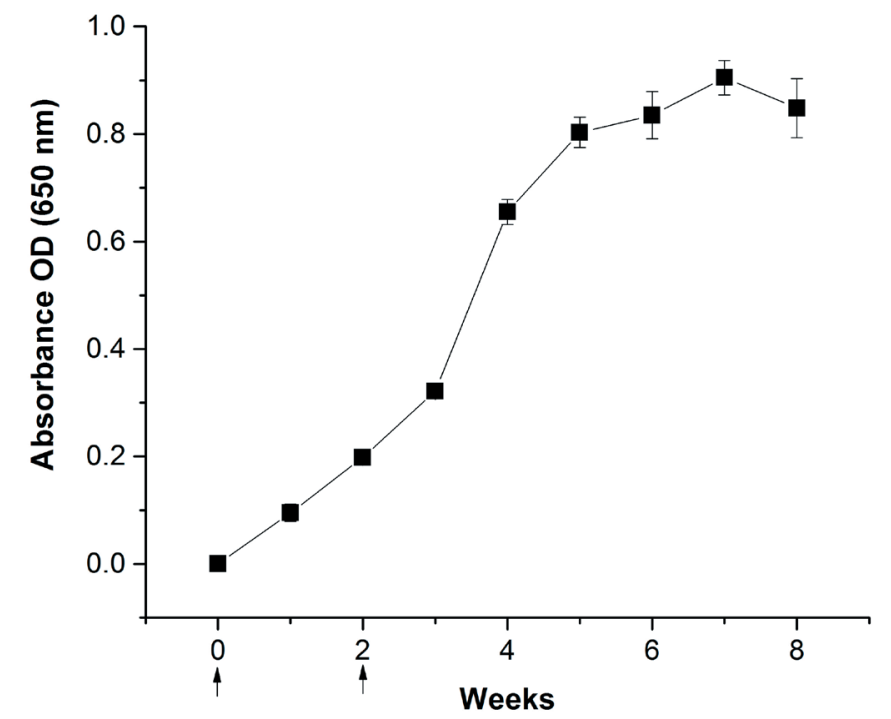

Fig. 2. The anti-melittin IgY activity during the 8 weeks of immunisation period. Antibody activities in the purified IgY solution (at 1:1,000 dilution) were measured by indirect ELISA and expressed as absorbance at $650 \mathrm{~nm}$. Values are the mean of quadruple samples. Vertical bars indicate the standard deviation. Arrows indicate the week of immunisation. 


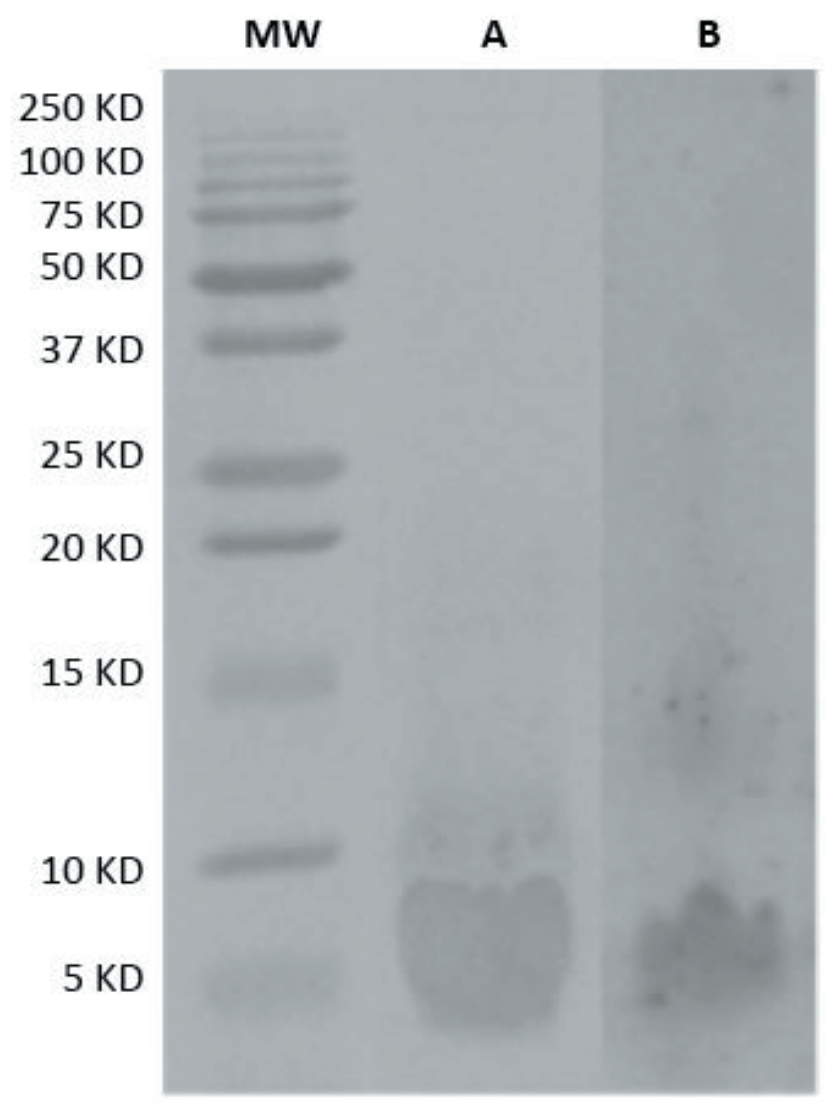

Fig. 3. Western blot of Sephacryl S-100 column size excluded bee venom protein fraction III (A) and Sigma melittin (B) with anti-melittin IgY. MW - Molecular weight.

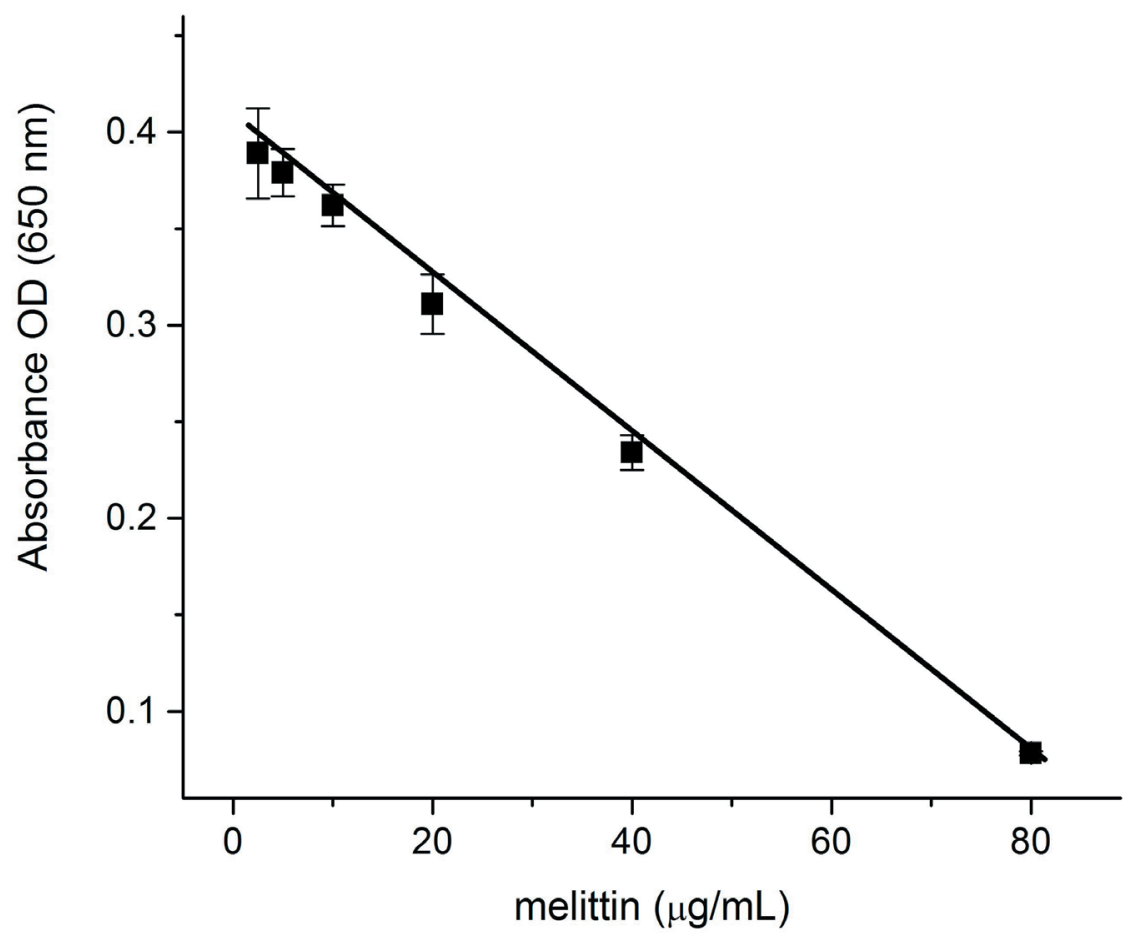

Fig. 4. The standard curve of indirect competitive ELISA for the melittin quantification with a working linear range of 2.5 to $80 \mu \mathrm{g} / \mathrm{mL}$. For each point, the concentration was calculated from the mean of quadruplicate determinations. Vertical bars indicate the standard deviation. 


\section{J. APIC. SCL. VOL. 59 N NO. 12015}

reacted with both purified and Sigma melittin (Fig. 3), indicating a satisfactory reactivity of the anti-melittin IgY polyclonal antibodies. The specificity of the anti-melittin IgY was further investigated by evaluation of the cross-reactivity between IgY and other bee venom proteins. Indirect ELISA results indicated no cross-reactivity between anti-melittin $\mathrm{lg} Y$ and other bee venom proteins (data not shown).

\section{Indirect Competitive ELISA}

A linear standard curve with a correlation coefficient of 0.95 was achieved with serial dilutions of melittin in the range of 2.5 to $80 \mu \mathrm{g} / \mathrm{mL}$ (Fig. 4). No detection was observed when non-specific IgY was used at the same concentration. The validity was further examined by precision tests. The intraassay coefficient of variation (intra-assay CV) in 10 replicates was $8.1 \%$ and the inter-assay coefficient of variation (inter-assay CV) in 8 replicates was 9.5\%. The amount of melittin measured in the bee venom was $54.75 \pm 8.55 \mu \mathrm{g} / \mathrm{mL}$ at a dilution of $1: 1,000$.

\section{Biotinylated DAS ELISA}

A double-antibody sandwich enzyme linked immunosorbent assay (DAS-ELISA) with biotinylated polyclonal IgY showed a detection range of $2.5-40 \mathrm{ng} / \mathrm{mL}$ (Fig. 5) with a correlation coefficient of 0.98 . The validity of the system was further examined by precision tests. The intra-assay CV determined by replicate measurements $(n=10)$ of serially diluted melittin was $6.8 \%$, and the inter-assay CV determined by eight independent measurements was $9.6 \%$. The amount of melittin in the bee venom samples $(n=6)$ measured by the system was

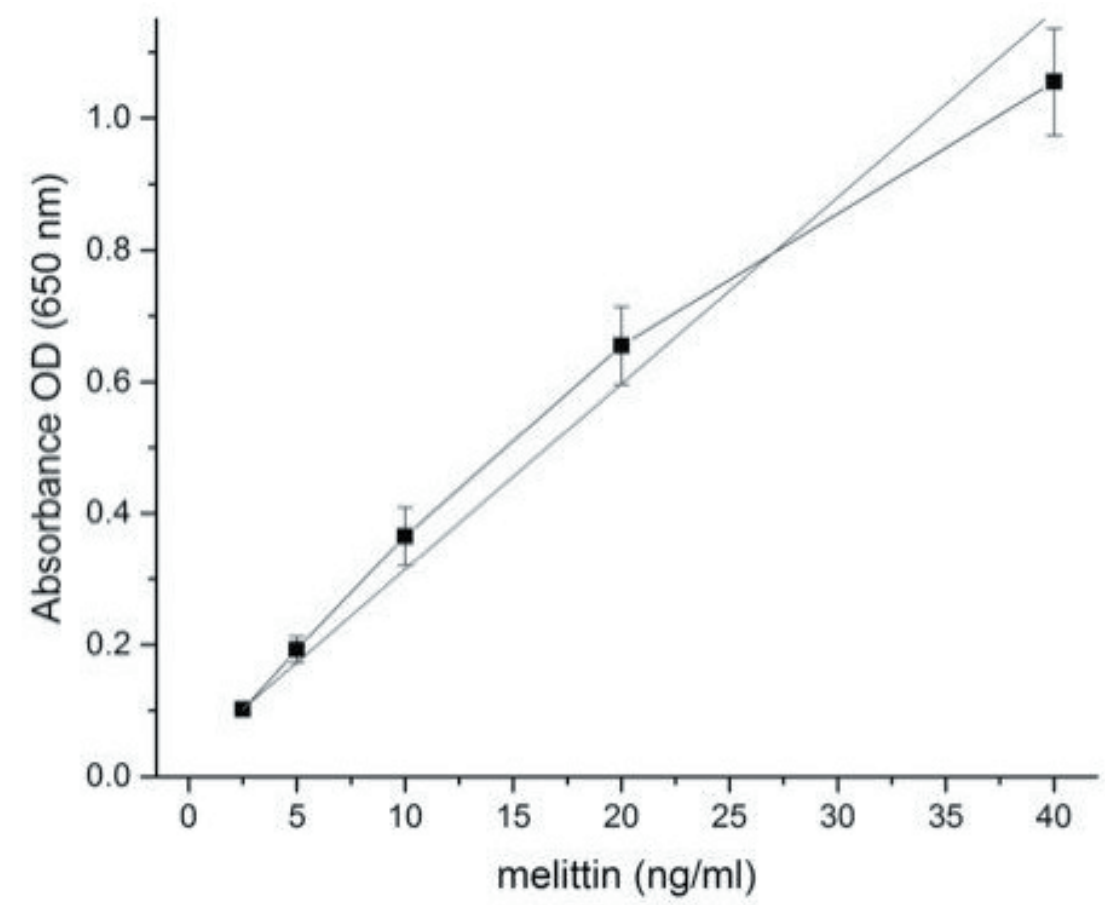

Fig. 5. The standard curve of double antibody sandwich ELISA for the melittin quantification with a working linear range of $2.5-40 \mathrm{ng} / \mathrm{mL}$. For each point, the concentration was calculated from the mean of quadruplicate determinations. Vertical bars indicate the standard deviation.

Table 1.

The melittin content in cosmetic products which contain bee venom (dilutions 1:2,000 to 1:8,000). The concentration of melittin in each product was calculated by a reference to the standard curve and expressed as micrograms of melittin per milliliter of product

\begin{tabular}{ccccc}
\hline \multirow{2}{*}{ Products } & \multicolumn{3}{c}{ Dilutions } & \multirow{2}{*}{ Mean } \\
\cline { 2 - 4 } & $1: 2,000$ & $1: 4,000$ & $1: 8,000$ & \\
\hline Cream 1 & $4.33 \pm 0.30$ & $4.69 \pm 0.74$ & $4.04 \pm 0.98$ & $4.35 \pm 0.74$ \\
\hline Cream 2 & $6.82 \pm 0.44$ & $6.58 \pm 0.91$ & $6.29 \pm 0.98$ & $6.56 \pm 0.74$ \\
\hline
\end{tabular}


$26.92 \pm 2.11 \mu \mathrm{g} / \mathrm{mL}$ at a dilution of $1: 1,000,000$. Melittin content in the two cosmetic products containing purified bee venom was measured in different dilutions. Dilutions at 1:2,000, 1:4,000, and $1: 8,000$ were appropriate for the standard curve for both products, with the mean of $4.53 \mu \mathrm{g} / \mathrm{mL}$ and $6.56 \mu \mathrm{g} / \mathrm{mL}$ each (Tab. 1). The amount of melittin was not disclosed on the product label.

\section{DISCUSSION}

Bee venom acupuncture has been widely used in traditional medicine to relieve pain and treat arthritis (Park et al., 2004). The pharmacological effects of bee venom, such as anti-bacterial, anti-viral, antitumor, anti-inflammatory, are attributed to the bioactive compounds of the bee vemon, which were separated by Sephacryl chromatography (Fig. 1a) (Juvvadi et al., 1996; Falco et al, 2013; Gajski and Garaj-Vrhovac, 2013; Lee et al., 2014b). The fractions I-IV were further electrophoresised to determine the proteins present in each fraction (Fig. 1b). Large enzymes, including phosphatase and hyaluronidase, were found in fraction I, phospholipase $A 2$ was found within fraction II, and low molecular weight peptides such as apamine, adolapine, MCD peptides, and melittin were found within fraction III (Banks and Shipolini, 1986; de Lima and Brochetto-Braga, 2003; Matysiak et al., 2011). Melittin is the major peptide in bee venom that constitutes $50 \%$ of bee venom dry weight, as noted by the high OD value and band thickness in SDS-PAGE. The broad range of molecular weight (2-10 kDa) shows spontaneous aggregation of melittin monomers into tetramers in aqueous solutions. (Qiu et al., 2005).

In dermatology, mellitin has been utilised for its anti-microbial activity and anti-inflammatory activity on skin-resident microorganisms such as $P$. acnes (Dosler and Gerceker, 2012; Lee et al., 2014a). Topical cosmetic products containing bee venom are gaining popularity for the treatment of acne and skin diseases. However, the cytotoxicity of melittin limits the amount of melittin that can be used in cosmetic formulations (Han et al., 2013; Jamasbi et al., 2014). Commercial cosmetic products compromise cytotoxicity simply by reducing the amount of melittin which also leads to an input cost reduction. However, there is no sensitive method to detect melittin in bee venom and melittin in those cosmetic products which contain bee venom. The reliable, accurate technique, HPLC, quantifies a protein, but the previously reported LOQ for melittin $(3.2 \mu \mathrm{g} / \mathrm{mL})$ is inadequate for a concentration measurement in cosmetic samples (Haghi et al., 2013). Such samples typically keep melittin levels below 0.05\% (unpubl. data). On the other hand, immunoassay is a cost-effective quantification method in which higher sensitivity may be achieved.

The chicken polyclonal IgY based ELISA system offers a couple of advantages over the use of monoclonal antibody. Due to a high phylogenic difference, chickens produce a high titer of antibody against a wide range of proteins including highly conserved mammalian proteins (Sunwoo et al., 2011). It was possible to obtain lgY egg yolk antibody without sacrificing or bleeding the animal but by simply collecting eggs on a daily basis. The yield of IgY antibody is higher than that of IgG antibodies obtained by conventional immunisation methods; i.e. $200 \mathrm{mg}$ of sera IgG can be obtained once, with approximately $5 \%$ constituting the specific lgG, whereas in chickens, approximately $3000 \mathrm{mg}$ of lgY can be harvested from egg yolks each month, with 5 to $10 \%$ constituting the specific lgY (Gujral et al., 2012a, b). The proportion of bovine proteoglycan-specific $\mathrm{lgY}$ in the total IgY was 9.0\% (Li et al., 1998). Similarly, the proportions of bovine and human lactoferrin-specific $\lg Y$ in the total lgY were $8.7 \%$ and $9.2 \%$, respectively (Sunwoo et al., 2011). Our results indicate that titer of anti-melittin polyclonal lgY antibody produced from chicken is higher (11.7\%) than antibody against typical mammalian proteins. This higher antibiody production is due to the high immunogenicity of melittin in chicken.

In the present study, we developed two different ELISA systems to detect melittin in bee venom and to detect the melittin in cosmetic products which contain bee venom. The indirect competitive ELISA was 1000 times less sensitive than biotinylated DAS ELISA when it came to detecting melittin, resulting in $2.5 \mu \mathrm{g} / \mathrm{mL}$ and $2.5 \mathrm{ng} / \mathrm{mL}$ of LOQ, respectively. The difference in sensitivity is mainly due to a strong covalent biotin-streptavidin interaction $\left(K_{d}=10^{-15} \mathrm{M}\right)$ between the detecting antibody and the enzyme of the DAS-ELISA system. Four biotin-binding sites per streptavidin molecule also offer greater sensitivity in the detection system (Green, 1990).

Indirect ELISA successfully measured melittin content in bee venom within close proximity to the previously measured concentration using HPLC-diode array detector-tandem mass spectrometry (HPLC-DAD-MS/MS), which is 46 - 53\% (Zhou et al., 2010). However, the detection of melittin in the two cosmetic samples was unsuccessful. With a lower dilution factor, the cream was not fully dissolved, whereas with a higher dilution factor, the concentration was out of range to be quantified using the indirect competitive ELISA (linear detection 
range of 2.5 to $80 \mu \mathrm{g} / \mathrm{mL}$ ). Therefore, the broader range as well as a higher detection limit provided by this system are inappropriate for quantifying small amounts of melittin in the cosmetics which contain bee venom, but the range and detection limit are more useful to quantify the higher melittin content present in bee venom.

Our result shows that biotinylated DAS-ELISA successfully quantifies melittin in those commercially available cosmetic products which contain bee venom (Tab. 1). The Limit of Quantitation (LOQ) of this developed DAS ELISA was approximately 1000 times and 400 times more sensitive than those obtained from reverse-phase HPLC (3.2. $\mu \mathrm{g} / \mathrm{mL}$ ) and HPLC-DAD-MS/MS $(1.0 \mu \mathrm{g} / \mathrm{mL}$ ), respectively (Zhou et al., 2010; Haghi et al., 2013). The cream sample dilutions $1: 2000,1: 4000$, and 1:8000, were appropriate for the detection system. Consistency of the results at different dilutions suggests that the other ingredients in the cream do not interfere with the assay at dilutions higher than 1:2000. The narrow detection range and low $L O Q$ is less preferable for detection of melittin in natural bee venom, but is appropriate for quantifying very low amounts in formulations. Therefore, depending on the presence of melittin in a sample, from microgram to nanogram levels, one of the two developed ELISA systems may be selected. Bee venom raw material suppliers and product manufacturers may use these detection systems to include the known amount of melittin as well as to declare the presence of melittin in their products.

\section{CONCLUSION}

Two cost-effective ELISA systems have been developed for melittin quantification using antimelittin IgY from hyperimmunised chicken egg yolk. Indirect competitive ELISA has a higher concentration range of detection, which allows for the measurement of natural concentrations of melittin in bee venom. Biotinylated DAS-ELISA system is highly sensitive, providing a very low concentration detection range, which is suitable for the quality control of cosmetic or pharmaceutical formulations.

\section{ACKNOWLEDGEMENT}

This work was carried out with the support of the Cooperative Research Program for Agriculture Science \& Technology Development (Project No. PJ01128901), Rural Development Administration, Republic of Korea. Authors acknowledge Dr. Suh as a co-corresponding author.

\section{REFERENCES}

Banks B. E. C., Shipolini R. A. (1986) Chemistry and pharmacology of honey bee venom. In: Piek T. (Ed) Venoms of the Hymenoptera. Biochemical, pharmacological and behavioural aspects. Academic Press. University of Michigan. Michigan, USA: 329-416.

Bojar R. A., Holland K. T. (2004) Acne and Propionibacterium acnes. Clinics in Dermatology 22(5): 375-379. DOl: 10.1016/j.clindermatol.2004.03.005

de Lima P. R., Brochetto-Braga M. R. (2003) Hymenoptera venom review focusing on Apis mellifera. Journal of Venomous Animals and Toxins including Tropical Diseases 9(2): 149-162. DOl: 10.1590/S167891992003000200002

Dosler S., Gerceker A. A. (2012) In vitro activities of antimicrobial cationic peptides; melittin and nisin, alone or in combination with antibiotics against Gram-positive bacteria. Journal of Chemotherapy 24(3): 137-143. DOl: 10.1179/1973947812y.0000000007

Falco A., Barrajon-Catalan E., Menendez-Gutierrez M. P., Coll J., Micol V., Estepa A. (2013) Melittin-loaded immunoliposomes against viral surface proteins, a new approach to antiviral therapy. Antiviral Research 97(2): 218-221. DOl: 10.1016/j.antiviral.2012.12.004

Gajski G., Garaj-Vrhovac V. (2013) Melittin: A lytic peptide with anticancer properties. Environmental Toxicology and Pharmacology 36(2): 697-705. DOl: 10.1016/j. etap.2013.06.009

Gauldie J., Hanson J. M., Shipolini R. A., Vernon C. A. (1978) Structure of some peptides from bee venom. European Journal of Biochemistry 83(2): 405-410. DOl: 10.1111/ j.1432-1033.1978.tb12106.x

Green N. M. (1990) Avidin and Streptavidin. Methods in Enzymology. 184: 51-67.

Gujral N., Suresh M. R., Sunwoo H. (2012a) Quantitative double antibody sandwich ELISA for the determination of gliadin. Journal of Immunoassay and Immunochemistry 33(4): 339-351. DOl: 10.1080/15321819.2012.655823

Gujral N., Lobenberg R., Suresh M., Sunwoo H. (2012b) In-Vitro and In-Vivo Binding Activity of Chicken Egg Yolk Immunoglobulin Y (IgY) against Gliadin in Food Matrix. Journal of Agricultural and Food Chemistry 60(12): 3166-3172. DOl: 10.1021/jf205319s 
Habermann E. (1972) Bee wasp venoms. Science 177(4046): 314-322. DOl: 10.1126/science.177.4046.314

Haghi G., Hatami A., Mehran M. (2013) Qualitative and Quantitative evaluation of melittin in honeybee venom and drug products containing honeybee venom. Journal of Apicultural Science 57(2): 37-44. DOl: 10.2478/jas2013-0015

Han S. M., Lee K. G., Park K. K., Park S. C. (2013) Skin sensitization study of bee venom (Apis mellifera L.) in guinea pigs and rats. Cutaneous and Ocular Toxicology 32(1): 27-30. DOl: 10.3109/15569527.2012.698402

Jamasbi E., Batinovic S., Sharples R. A., Sani M., Robins B., Roy M., Wade J., Separovic F., Hossain M. A. (2014) Melittin peptides exhibit different activity on different cells and model membranes. Amino Acids 46(12): 2759-2766. DOl: 10.1007/s00726-014-1833-9

Juvvadi P., Vunnam S., Merrifield R. B. (1996) Synthetic melittin, its enantio, retro, and retroenantio isomers, and selected chimeric analogs: Their antibacterial, hemolytic, and lipid bilayer action. Journal of the American Chemical Society 1 18(38): 8989-8997. DOl: 10.1021/ja954291 1

Koh P. S., Seo B. K., Cho N. S., Park H. S., Park D. S., Baek Y. H. (2013) Clinical effectiveness of bee venom acupuncture and physiotherapy in the treatment of adhesive capsulitis: a randomized controlled trial. Journal of Shoulder and Elbow Surgery 22(8): 1053-1062. DOl: 10.1016/j. jse.2012.10.045

Larsson A., Karlssonparra A., Sjoquist J. (1991) Use of Chicken antibodies in enzyme immunoassays to avoid interference by rheumatoid factors. Clinical Chemistry 37(3): $411-414$.

Lee M. T., Sun T. L., Hung W. C., Huang H. W. (2013) Process of inducing pores in membranes by melittin. Proceedings of the National Academy of Sciences of the United States of America 1 10(35): 14243-14248. DOI: 10.1073/pnas.1307010110

Lee W. R., Kim K. H., An H. J., Kim J. Y., Han S. M., Lee K. G., Park, K. K. (2014a) Protective effect of melittin against inflammation and apoptosis on Propionibacterium acnes-induced human THP-1 monocytic cell. European Journal of Pharmacology 740: 218-226. D0l: 10.1016/j. ejphar.2014.06.058
Lee W. R., Kim K. H., An H. J., Kim J. Y., Chang Y. C., Chung H., Park Y. Y., Lee M. L., Park K. K. (2014b) The Protective Effects of Melittin on Propionibacterium acnes-Induced Inflammatory Responses In Vitro and In Vivo. Journal of Investigative Dermatology 134(7): 1922-1930. DOl: 10.1038/jid.2014.75

Leyden J. J. (2001) The evolving role of Propionibacterium acnes in acne. Seminars in Cutaneous Medicine and Surgery 20(3): 139-143. DOl: 10.1053/sder.2001.28207

Li X., Nakano T., Chae H. S., Sunwoo H., Sim J. S. (1998) Production of chicken egg yolk antibody (lgY) against bovine proteoglycan. Canadian Journal of Animal Science 78(3): 287-291.

Matysiak J., Schmelzer C. E. H., Neubert R. H. H., Kokot Z. J. (2011) Characterization of honeybee venom by MALDITOF and nanoESI-QqTOF mass spectrometry. Journal of Pharmaceutical and Biomedical Analysis 54(2): 273-278. DOl: 10.1016/j.jpba.2010.08.020

Park H. J., Lee S. H., Son D. J., Oh K. W., Kim K. H., Song H. S., Kim G. J., Oh G. T., Yoon D. Y., Hong J. T. (2004) Antiarthritic effect of bee venom - Inhibition of inflammation mediator generation by suppression of NF-kappa B through interaction with the p50 subunit. Arthritis and Rheumatism 50(1 1): 3504-3515. DOl: 10.1002/art.20626

Qiu W. H., Zhang L. Y., Kao Y. T., Lu W. Y., Li T. P., Kim J., Sollenberger G. M., Wang L. J., Zhong D. P. (2005) Ultrafast hydration dynamics in melittin folding and aggregation: Helix formation and tetramer self-assembly. Journal of Physical Chemistry B 109(35): 16901-16910. DOl: 10.1021/jp0511754

Raghuraman H., Chattopadhyay A. (2007) Melittin: A membrane-active peptide with diverse functions. Bioscience Reports 27(4-5): 189-223. DOl: 10.1007/ s10540-006-9030-z

SAS Version 9.1.3 (2002-2004) Help and Documentation. SAS Institute Inc. Cary, NC, USA.

Schade R., Calzado E. G., Sarmiento R., Chacana P. A., Porankiewicz-Asplund J., Terzolo H. R. (2005) Chicken egg yolk antibodies (lgY-technology): A review of progress in production and use in research and human and veterinary medicine. ATLA Alternatives to Laboratory Animals 33(2): 129-154. 
Sunwoo H., Gujral N., Suresh M. (2011) Competitive and double antibody sandwich ELISA for the quantification of lactoferrins by using monoclonal and chicken egg yolk IgY antibodies. Journal of Immunoassay and Immunochemistry 32(2): 79-92. DOl: 10.1080/15321819.2010.543218

Terwilliger T. C., Weissman L., Eisenberg D. (1982) The structure of melittin in the form I crystals and its implication for melittin's lytic and surface activities. Biophysical Journal 37(1): 353-361.
Zhou J. H., Zhao J., Zhang S. X., Shen J. Z., Qi Y. T., Xue X. F., Li Y., Wu L. M., Zhang J. Z., Chen F., Chen L. Z. (2010) Quantification of melittin and apamin in bee venom lyophilized powder from Apis mellifera by liquid chromatographydiode array detector-tandem mass spectrometry. AnaIytical Biochemistry 404(2): 171-178. DOl: 10.1016/j. ab.2010.05.014 